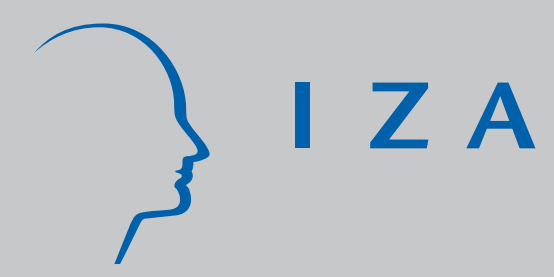

IZADP No. 4017

Money Matters:

Evidence from a Large-Scale Randomized Field

Experiment with Vouchers for Adult Training

Dolores Messer

Stefan C. Wolter

February 2009 


\title{
Money Matters: Evidence from a Large-Scale Randomized Field Experiment with Vouchers for Adult Training
}

\author{
Dolores Messer \\ University of Bern \\ Stefan C. Wolter \\ Swiss Coordination Centre for Research in Education, \\ University of Bern, CESifo and IZA
}

Discussion Paper No. 4017
$\quad$ February 2009

IZA

P.O. Box 7240

53072 Bonn

Germany

Phone: +49-228-3894-0

Fax: +49-228-3894-180

E-mail: iza@iza.org

Any opinions expressed here are those of the author(s) and not those of IZA. Research published in this series may include views on policy, but the institute itself takes no institutional policy positions.

The Institute for the Study of Labor (IZA) in Bonn is a local and virtual international research center and a place of communication between science, politics and business. IZA is an independent nonprofit organization supported by Deutsche Post Foundation. The center is associated with the University of Bonn and offers a stimulating research environment through its international network, workshops and conferences, data service, project support, research visits and doctoral program. IZA engages in (i) original and internationally competitive research in all fields of labor economics, (ii) development of policy concepts, and (iii) dissemination of research results and concepts to the interested public.

IZA Discussion Papers often represent preliminary work and are circulated to encourage discussion. Citation of such a paper should account for its provisional character. A revised version may be available directly from the author. 
IZA Discussion Paper No. 4017

February 2009

\section{ABSTRACT \\ Money Matters: \\ Evidence from a Large-Scale Randomized Field Experiment with Vouchers for Adult Training}

This paper presents the results of a randomized experiment analyzing the use of vouchers for adult training. In 2006, 2,400 people were issued with a training voucher which they were entitled to use in payment for a training course of their choice. User behavior was compared with a control group of 14,000 people. People in the treatment and in the control group were not aware at any time that they were part of an experiment. The experiment shows that the voucher had a significant causal impact on participation in training modules. Nevertheless, the increase was partially offset by a deadweight loss in excess of fifty percent.

JEL Classification: $\quad$ C93, I22, J24

Keywords: field experiment, voucher, adult education, training, Switzerland

Corresponding author:

Stefan C. Wolter

University of Bern

Centre for Research in Economics of Education

P.O. Box 8573

Schanzeneckstrasse 1

3001 Bern

Switzerland

E-mail: stefan.wolter@vwi.unibe.ch 


\section{Introduction 1}

Lifelong learning is a high priority issue in the EU in particular. Lifelong learning is mainly seen as promoting the employability of a country's citizens. Given the aging populations of most European countries, preserving the human capital of the labor force is more important now than ever. In recognition of this, the EU Lisbon Protocol includes adult education targets. The aim by 2010 is to have $12.5 \%$ of adults participating in further education in any given month. Educational policies in many countries are based on a belief that these aims cannot be achieved by market forces alone, and require targeted government intervention in the adult education market. These interventions may comprise both monetary and non-monetary measures. Government subsidization of adult education may be of two basic kinds, demand-oriented or supply-oriented. To enhance allocative and productive efficiency, direct funding of subjects seeking adult education (demand-oriented) is becoming more common than funding the education providers (supply-oriented). Demand-oriented adult education funding is possible through the use of various tools, including adult education vouchers (see Oosterbeek 1998 or Oosterbeek and Patrinos 2009).

The experiment described in this paper is also motivated by the fact that adult education vouchers are in actual use in some countries and are not a hypothetical funding tool. In all known adult education voucher models, launch was not preceded by a real-life trial period that would have been useful in testing the workability of the tool and establishing that the necessary framework was in place to enable the model to succeed. Ex-post evaluations also tend to fail because it is impossible to reconstruct many key parameters in retrospect, and because universal launch means there is no control group available that could be used for reference purposes. Against this background, the experiment presented

\footnotetext{
${ }^{1}$ The authors wish to thank the Federal Office for Professional Education and Technology for financial and the Swiss Federal Statistical Office for logistic support in the conduct of the experiment. The authors are also grateful for the opportunity to utilize Swiss Labor Force Survey (SLFS) data. The second author also wishes to thank CESifo for their hospitality and stimulating working conditions while preparing this paper. Any remaining errors are entirely the authors' responsibility.
} 
here does two things: it provides data of relevance to the prospective potential launch of an adult education voucher system, and also provides information of interest in evaluating the efficacy and efficiency of existing models.

The field experiment was conducted in Switzerland in the 2006-2007 period. Switzerland's adult education participation rates are in the upper range of the EU average. At present, adult education policies and the adult education market in Switzerland (cf. OECD 2003) are highly free-market based in comparison with other industrialized countries. The relatively low level of government intervention is being called into question in Switzerland (as in other countries), one reason being the significant variation in adult educational rates between different sectors of the population. A vigorous educational policy debate is currently raging in Switzerland as to whether this problem can be addressed with adult education vouchers. Debate is additionally fuelled by the fact that one canton (Geneva) has had a real-life, universal voucher model for adult education for a number of years now and the fact that a constitutional obligation to regulate adult education for the whole of Switzerland through a Federal Adult Education Act exists since 2006. The latter was also the starting point for investigating the workability of an adult education voucher system in the form of a scientifically designed field experiment in Switzerland.

This paper is structured as follows: the next section states briefly why the government should intervene in adult education funding at all. Reference will be made to a few cases of actual implementation of demand-oriented adult education tools, but all of these are insufficiently evaluated. Section 3 provides a detailed description of the experiment performed. Section 4 gives descriptive results, and section 5 compares and contrasts the experimental and control group in terms of econometric analyses. The paper concludes with the preliminary conclusions to be drawn from the experiment conducted. 


\section{Public funding of life-long learning}

Although public funding of life-long learning is politically undisputed in virtually all European countries, evidence and economics-based arguments for this kind of intervention is thin on the ground. Government intervention in the adult education market can be justified if a general or partial excessively low participation in adult education is a consequence of positive externalities of education. Suboptimal participation in adult education in such a case would be because part of the return on adult education does not directly accrue to those engaging in adult education/training, and this in turn would justify public subsidizing of the cost of adult education. Pursuing a similar line of argument, one can assume that non-education generates social costs, i.e. negative externalities, which the State can reduce by providing subsidies to encourage educationally inactive individuals to opt for adult education.

Whatever the average level of participation in adult education, participation levels are unequally distributed in almost all countries. Individuals with low educational attainment and the elderly are significantly less likely to pursue adult education (see Bassanini et al. 2005). These distributional aspects can also justify State funding, if education is not within the financial grasp of all citizens and there is no credit market to serve funding needs. The lack of a functioning credit market for funding adult education is no surprise, as investment in adult education is associated with high default and return risks, which might militate against the establishment of a functioning private credit market ${ }^{2}$. It is important to bear in mind that, if education generates private earnings only, equable distribution can be achieved if the State provides loans to replace the missing credit market. In this scenario, the government merely provides an advance on the cost of education rather than subsidizing it. In other words, the loans would not be provided to adult education participants interest-free. Government-subsidized education is hence justified only if the market outcome were causing suboptimal demand for education.

\footnotetext{
${ }^{2}$ Whether credit limitations are indeed the reason for poor adult education participation is not undisputed (see Brunello and De Paola 2009).
} 
Differences in adult education participation rates may also be due to differences in return on adult education. If returns on adult education are actually very low for certain population groups, differences in adult education rates might in fact be economically efficient (see Vignoles et al. 2004) despite running contrary to the notion of equitability of distribution 3 . To qualify matters, it is important to note that the - in some cases - low private monetary gains from training are more usually a consequence of labor market friction rather than indicating that training/education is ineffective (see e.g. Conti 2005). Although labor market frictions of the kind lead to a higher participation of employers in covering the cost of adult education (see Brunello and Bassanini 2008), the drawback is that employees who are not funded by their employers have no appreciable monetary incentives to invest in adult education themselves. This is another reason for the State to subsidize adult education, so as to give individuals with no employer support the opportunity to engage in adult education. This also includes non-employed individuals whose chances of entering the workforce stand to gain from adult education.

The non-monetary costs of education are just as plausible a reason for differences in adult education participation rates as are a lack of monetary gains or credit limitations. It seems logical that these non-monetary costs will be higher for individuals with lower educational attainment than those with higher educational attainment, and it is logical that this would be one reason for the major differences in adult education participation rates If that is indeed the case, a more evenly distributed adult education participation rate might be achievable through increased financial incentives, but it would be worth exploring whether

\footnotetext{
${ }^{3}$ Of interest here are sources in the literature suggesting that returns on adult education are appreciable only if a certain critical level of formal educational attainment is already in place (see Brunello 2001). This would indicate that high participation in adult education is best promoted by a good basic education, i.e., government investment in early education would be more effective and more efficient in every respect (see Cunha et al. 2005 or Silles 2007).

${ }^{4}$ This mainly refers to cognitive costs, which make education more of an effort for some people than others and deter the latter from pursuing adult education (see Heckman et al. 2005).
} 
other measures might not be more effective and efficient.

It is striking that, in Europe at least (but not only; see OECD 2004a\&b), most countries are intervening heavily in the adult education market regardless of whether this kind of intervention is justified on the basis of scientific evidence. Intervention may be in the form of subsidizing the providers of adult education, tax exemptions for spending on education by individuals and employers, and in the form of actively pushing demand.

An overview of adult education support measures in the EU-15 countries (EIM 2005) shows that more than 90 different tools are in use today. Although voucher models are in the minority, they are in actual current use in a number of European countries. In most cases, these funding tools are subject to restrictions in terms of time, region or entitled individuals. This makes it difficult to generalize between the models. Current education voucher models are provided by the regional chambers of trade in Austria (see Lachmayr 2004), the Training Cheque in the canton of Geneva (Switzerland) (see Wolter et al. 2003), the Training Cheque in Belgium (see Bollens 2005), adult education vouchers in some Italian regions (set up by the national Ministry of Labor with European Social Fund monies) and the North Rhine-Westphalian Training Check (since 2006) ${ }^{5}$.ne thing all these real-life voucher models have in common is that they involve heavy financial investment but there is no real scientifically justifiable evaluation of their impact. Therefore, these models will not be presented in greater detail in this paper ${ }^{6}$

\footnotetext{
${ }^{5}$ In a limited experiment in South Tyrol (1996/7), 1,500 individuals were sent three vouchers each worth 25 euros (see Tappeiner and Trompedeller 2002). The design of this exercise is not comparable to ours due to the absence of a proper control group. Approximately $7 \%$ of the issued vouchers were redeemed.

${ }^{6}$ This paper does not look in detail at voucher trials in other areas of education (e.g. in the compulsory school system where voucher trials have been combined with randomized trials on several occasions; see Ladd 2002, Krueger and Zhu 2004), or voucher trials directed at companies rather than individuals, or those intended for other services rather than adult education/training, an example being the voucher trial for job mediation services in Germany (see Winterhager et al. 2006). The experiment described is also not suited to analyze changes in the supply of education, as was possible with other vouchers experiments (e.g. for the
} 


\section{The experiment}

\subsection{Experiments as an evaluation tool}

Experiments are an increasingly common economic research tool. Their advantage over other investigating methods is the greater ease in measuring and establishing causal effects. The experimental design makes it easier to control for imponderables and hence eliminate any results bias (see Rubin 1974). Although econometric evaluation methods have made great strides in the past two decades, some issues are so complex that statistical methods produce robust outcomes only if stringent assumptions are applied. Experiments are therefore especially likely to produce more meaningful outcomes in situations where social interactions or complex institutional structures play an important role (see Manski, 2005) 7 . Experiments can be conducted either in a controlled artificial laboratory situation or in real life. In the latter case, observers can choose between natural and social experiments. In natural experiments, researchers benefit from the fortuitous circumstance that emergent changes have created a situation that sets the scene for an experiment, despite the lack of a formal experimental design 8 . However, naturally occurring developments of this kind cannot be relied upon to take place when they are needed, so it is necessary in the case of some studies to create artificial situations in which parameters of a real-life observable state are manipulated deliberately by the scientist in order to investigate a specific issue.

Although lab experiments enable more stringent control of exogenous variables, pre-school daycare supply, see Viitanen 2007).

${ }^{7}$ Although randomized trials are the gold standard of research in the USA in particular, experimental research has been slow to become established in education research (see Cook 2003, Oakley 2003 and Angrist 2004), as reflected in the very small number of experimental field studies. Nevertheless, the fact that questions of causality - in the area of education as in other fields - are best answered by experimental research is undisputed (see Webbink 2005).

${ }^{8} \mathrm{~A}$ prime example of a natural experiment of the kind are extensions of compulsory schooling times, which allow the impact of education on labor market outcomes to be analyzed as in an experiment (see e.g. Pischke 2004) or the change in the loans and grant system for college studies (see Rothstein and Rouse 2007). 
not all scientific objectives are amenable to investigation in a lab experiment ${ }^{9}$ In this case, where the objective was to evaluate the impact of vouchers on participation in adult education, it was necessary to design a field experiment which was to take place in the subjects' natural environment. Active experimental interventions of this kind to analyze particular connections are a longstanding tradition in economic research, especially in the field of government-funded social and labor market programs (see e.g. LaLonde 1986). At the same time, their use is limited both because of the financial resources required for experimental simulation of measures in the field, and moral/ethical concerns surrounding this kind of evaluation. If it is clear ex ante that individuals participating in the experiment are likely to derive advantages or disadvantages from the experiment, it may be difficult to justify and conduct such experimentation.

Compared with evaluations of ongoing programs, experimental evaluation of measures that have not yet been implemented is compounded by the fact that the experimental situation may seem so artificial to the treatment group as to falsify their behavior. Therefore, two factors are crucial to the success of a field experiment. Firstly, the experimental setting must seem so natural to the subjects that their actions in the experimental situation correspond to how they would react if the situation were not experimental but real ${ }^{10}$ If an experiment is very different from real life, it is doubtful whether the same effects would be observed in the corresponding real-life situation. Secondly, there are abundant examples showing that both the individuals in the experimental group and individuals in the control group may act other than in real life simply become of their awareness of being participants in an experiment. Ideally, an experiment must be designed such that all participants are unaware that their behavior is

\footnotetext{
${ }^{9}$ Examples of randomized field experiments are more and more frequent in cases where the key environmental variables are seen only in the field and cannot be reproduced in the lab. Some studies also investigate items in field experiments which were previously studied only in a lab setting (for a selection of current experiments, see Bettinger and Slonim 2006, Meier 2006, Falk 2007, Fehr and Goette 2007, Gneezy and List 2007 or Kling, Liebman and Katz 2007).

10،...representativeness of the environment, rather than representative of the sampled population, is the most crucial variable...' (List 2006)
} 
being investigated. This ideal setting corresponds to a so-called natural field experiment (see Levitt and List 2008, pp 26-27).

In recognition of these difficulties, considerable planning and thought went into designing the experiment described here to ensure that 1) the experimental situation approximated a real-life situation as closely as possible so as to enable the results to be generalizable to real life, 2) the experimental group subjects were not aware that their actions were under observation, as they would otherwise have changed their behavior for strategic reasons; 3) control group subjects remained entirely oblivious to the experimental situation, i.e., they behaved exactly as they would have done without the experiment, and 4) the observers did not intervene during the actual performance of the experiment and hence were unable to influence the outcomes.

\subsection{Experimental design and propositions}

The key study objectives were to establish the following:

a) Does the issuance of adult education vouchers cause an increase in uptake of continuous education measures, and if so, among whom?

b) Is it possible to calculate the deadweight loss, i.e., the proportion of the voucher value that is redeemed but only for adult training that the beneficiaries would have paid for themselves in any case had they not received adult education vouchers?

c) Is there any price sensitivity to the face value of the voucher, i.e., does utilization of the voucher depend on its value?

d) Does it matter whether vouchers are issued on their own or whether they come with an offer of advice and support?

Questions a) and b) are answerable only if the experimental group (individuals receiving vouchers) can be compared with a control group differing from the experimental group solely and exclusively in terms of their not having received a voucher. Allocation to the experimental group/control group must therefore be based on random assignment. Questions c) and d) can be answered 
only if not all individuals in the experimental group received the same vouchers. Again, allocation within the experimental group must be on a randomized basis.

The experiment benefited from the fact that the SLFS sample population was raised significantly at the beginning of the century prior to being reduced more recently because of financial constraints. The SLFS is structured according to a rotating panel principle in which the respondents are interviewed five years in succession. As a result, about one-fifth of the respondent population is replaced every year. The additional reduction in the sample population yielded the opportunity to select a random sample for the experiment from the approximately 6,000 individuals who would otherwise have been scheduled to continue participating in the next round of interviews. All these individuals had already been interviewed in 2005, and most of them had also been interviewed in former years, and had been removed from the interview schedule in 2006 because of the sample size reduction. Based on a potential voucher redemption rate and the associated costs, group sizes were determined for the experiment that were intended to produce a sufficient number of observations to satisfy statistical demands. The random sample comprised a total of 2,437 individuals who were further divided up according to the criteria of face value of the voucher and provision of advice and guidance (see Table 1).

Table 1: Division of the experimental group (number of observations)

\begin{tabular}{c|cccc|c} 
& \multicolumn{4}{|c|}{ Face value } & \\
Advice & $\mathbf{2 0 0} \mathbf{~ C H F}$ & $\mathbf{7 5 0} \mathbf{~ C H F}$ & $\mathbf{1 5 0 0} \mathbf{~ C H F}$ & Total \\
\hline Yes & 408 & 407 & 404 & 1,219 \\
No & 407 & 407 & 404 & 1,218 \\
\hline Total & 815 & 814 & 808 & 2,437
\end{tabular}

The experimental group is matched by a control group of about 14,000 individuals who were interviewed by the SLFS as scheduled in 2006 and met the criterion of having been interviewed in 2005. The experimental design enables

${ }^{11} 1 \mathrm{CHF}$ is equivalent to about $1 \mathrm{USD}$ or $0.62 \mathrm{EUR}$. 
the use of longitudinal data as well as cross-sectional information, which is important with respect to the issue of interest here. For example, it is well known that prior adult education participation is the best predictor for participation in adult education at a given point in time. Although this information could also be obtained on the basis of retrospective surveys, the opportunity to observe the control and experimental group pre-experiment provides a much more reliable method.

With respect to the control and experimental group, age was the only limitation. Only subjects aged 20 to 60 were entitled to receive vouchers. Under-20s would be likely to be still undergoing education or training, and over-60s would be likely to be retired pensioners. There were no limitations as to employment status, as increasing the skills of non-employed individuals may be a goal of the State.

\subsection{Experimental conduct and schedule}

The 2,400 randomly selected individuals received a letter from the Swiss Federal Statistical Office during the first days of January $2006^{12}$ containing the adult education voucher. The letter stated that the voucher was in reward for past participation in the Swiss Labor Force Survey. It was signed by the General Director of the Swiss Federal Statistical Office to eliminate any doubts as to the legitimacy of the voucher. No public-domain information was generated at any point during the experimental period, to ensure that voucher recipients were unaware that the dispensing of the voucher was part of an observational study.

For half of the vouchers, the letter contained a telephone hotline number offering free advice. This service was provided by a professional organization specializing in adult education consulting. The consultations were recorded and evaluated

\footnotetext{
${ }^{12} \mathrm{~A}$ longer voucher redemption time would have been desirable but legal and political verification processes delayed voucher issuance.

${ }^{13}$ Data protection mechanisms unfortunately prevent us from linking specific information from the advice sessions with SLFS data. We can only use information on the type of voucher, i.e. we know who was offered the advice option, but not whether they actually availed of the offer.
} 
Recipients were entitled to use the voucher for an adult education module of their choice. There were no restrictions on the content of the adult education module because the intention was to use the choices as a basis for an efficiently designed adult education voucher system later on.

Recipients were allowed to use the voucher to pay for an ongoing adult education module. The final date for starting an adult education program was July 2006. This was done in a bid to maximize the redemption timescale. Though problems might have occurred at the beginning and end of the redemption period, the temporal pattern of redemptions showed a significantly lower number of redemptions in the first and last month of the experiment and a fairly stable redemption pattern in the February to June period, peaking in mid-experiment (April). The time pattern for voucher redemptions does not suggest any unintentional special effects. To redeem the voucher, it was necessary to send the voucher with the course organizer's invoice to the Federal Office for Professional Education and Technology, which in turn paid out the amount to participants. The federal agency conducted spot checks to verify that the adult education uptake and invoices were bona-fide. Toward the end of June, the experimental subjects were surveyed for the Swiss Labor Force Survey as in previous years. To enable later linkage of the latter survey data with the experimental data, the participants were required at the end of the survey to say whether they consented to data linkage. This ensured both that the replies to the Swiss Labor Force Survey's standard questions were not skewed because of linkage with the adult education voucher, and also ensured that data protection concerns were addressed.

\section{Descriptive results and voucher utilization}

Out of the 2,437 individuals receiving adult education vouchers, 1,888 (77.5\%) took part in the SLFS at the end of June 2006 Fortunately, hardly any of

\footnotetext{
${ }^{14}$ The long-standing mean SLFS participation rate is $83 \%-89 \%$. Analysis of participation rates for 2006 however showed a significantly lower participation rate and no significant dif-
} 
the respondents objected to linkage of the SLFS data with the experiment. For data protection reasons, we were not allowed to analyze the data of individuals in the experimental group who did not take part in the 2006 survey but for whom we had data at least from the 2005 Swiss Labor Force Survey. However, for the total sample of voucher recipients $(2,437)$, we had a reduced dataset of background variables (prior education/training, gender, region of residence and two age categories). If we compare the estimates from the SLFS data with the reduced dataset for all voucher recipients, we find no qualitative differences between the two sets of calculations. This suggests that the non-participation in the 2006 SLFS of slightly more than $20 \%$ of the voucher recipients does not affect the results. Refusal was the reason for non-participation in very few of the subjects; the main reason for non-participation was that many subjects could no longer be contacted (loss to follow-up).

The evaluation concerns adult education participation in courses that cost money. Like other adult education statistics approaches, the SLFS differentiates between different forms of formal and informal adult education, and the participation rates naturally vary accordingly. The crucial aspect in government-funded adult education is that it is intended to increase opportunity for attending feebased adult education offerings. Therefore, the statistical module selected from the adult education modules in the SLFS available was the one in respect of which SLFS participants are subsequently asked whether they had attended fee-based courses within the past 12 months ${ }^{15}$

Adult education participation is investigated in terms of the effect of gender,

ference between the experimental and the control group. An additional non-response analysis disclosed no particularly conspicuous non-response pattern.

${ }^{15}$ This shows the drawback of the reduced voucher redemption period, which arose because of legal problems. When SLFS participants are asked whether they attended fee-based adult education courses within the past 12 months, it is always possible that experimental group contains individuals who attended courses in the second half of 2005 before receiving the education vouchers. Although this possibility limits the precision of the conclusion as to the quantitative impact of the voucher on adult education participation, we believe this cosmetic flaw in the experimental design does not compromise the conclusions from this experiment. 
prior educational attainment, age, nationality and region of residence. The latter is operationalized such that urban districts are contrasted with rural districts. The underlying hypothesis is that demand for adult education also depends in the short term from the range of adult education opportunities on offer ${ }^{16}$. It is logical to assume that adult education opportunities are more numerous and far-ranging in urban than in rural regions. For subjects in paid employment, there are additional control variables such as type of employment (employee vs. self-employed), hours of employment (part-time), salary, size of company, and position in the company hierarchy.

449 of the total 2,437 voucher recipients redeemed their vouchers, representing a redemption rate of $18.4 \%$. Redemption rates differed depending on the face value of the voucher (see Table 22). Both the CHF 750 and CHF 1,500 vouchers were redeemed significantly more frequently than the CHF 200 voucher, but the rates of redemption for the higher amounts did not differ significantly from each other. The conclusion is that the redemption rate seems to demonstrate a price elasticity response to the face value of the voucher, but the relationship is non-linear. Gender and prior educational attainment of the voucher recipient also have a significant effect on the probability of redeeming a voucher. These results are congruent with those of other adult education participation studies. In contrast, the redemption rate did not depend on whether the voucher was coupled with an advice option; nor was recipient ag ${ }^{17}$ a significant factor.

The non-effect of the advice option in terms of voucher redemption rate might be called into question if the advice offering had been poorly designed. A number of points are of interest here. Subjects were not actively advised (i.e., advice was not provided unprompted), but were required to take the initiative and seek advice. However, given the low barriers to receiving advice, and the extent and price (free of charge) of the advice option, the advice option in the experiment

\footnotetext{
${ }^{16}$ More specific analyses for individual cities were performed also. These only showed that adult education participation among employed voucher recipients was higher in the city of Zurich than in rural areas.

${ }^{17}$ The variable of age was tested both in the linear and in a non-linear specification.
} 
is likely to have been better designed than would have been the case in real life. Therefore, the observation that an advice option - even if availed of - has no perceptible effect in terms of increasing adult education participation rates, is an outcome that would have to be taken into account when launching voucher systems in real life. The outcome also calls into question the effectiveness of existing government support of adult education, even if it was not possible to test whether users of the support option embarked upon better, i.e. more suitable, adult education options than subjects who did not avail of the support service.

\section{Econometric analysis of the impact of vouchers on training activities}

\subsection{Adult education participation in the experimental and control group}

Comparison of adult education participation in the experimental vs. control group (see Table 3 immediately shows that adult education participation in the experimental group (approximately 40\%) was more than 20 percentage points higher than the voucher redemption rate. In other words, more than $50 \%$ of the experimental group participated in adult education without utilizing the voucher. As already mentioned, one reason might be that the voucher arrived after the subjects had done the course. Another possible reason is that subjects participated in courses that they were not called upon to pay themselves, and hence would not have been able to use the voucher for payment. In accordance with this hypothesis we find that approximately half (55\%) of individuals who took part in fee-based courses and did not utilize vouchers for payment belong to this latter category (participation with a contribution of employers, see also 5.5p. Thus, the population of subjects who funded their own course despite theoretically having had the option of using a voucher for that purpose is about half of those who were active in training and not using the voucher.

Comparison between the experimental and control group reveals that age is not 
a significant factor in the voucher recipient population. In the subpopulation of employed voucher recipients, company size is not significant. Therefore the vouchers seem to have promoted equitability in adult education participation in terms of some criteria at least, compared to participation rates without vouchers. However, the vouchers emphasized some factors, such as the proportion of female participation. The latter effect is also observed in real-life models. It is also evident in both groups that course attendance during the previous year (course 2005 variable) is significantly associated with adult education participation the following year.

\subsection{Vouchers increased participation}

Comparing the experimental and control group to test whether voucher receipt had a significant impact on adult education participation shows that the vouchers brought about an almost six percentage point increase in participation rates (see Table 4). This almost exactly corresponds to the simple comparison of means between the participation rates in the two groups, indicating that the randomly selected sample achieved its intended purpose for the experiment. A breakdown of vouchers by face value shows that the vouchers with the highest face values significantly raised levels of participation in adult education (by practically the same level for the two amounts), but that the voucher with the lowest face value produced no significant increase in adult education participation levels. Looking at the employed population only, the total effect of the voucher is somewhat smaller but the voucher with the highest face value has approximately double the impact than intermediate-value vouchers (see Table 5p. For the employed population at least, there is a virtually linear impact of voucher face value on adult education participation, with the lowest-value voucher again producing virtually no effect. Though this latter outcome was in line with our expectations, its importance should not be underestimated. A number of voucher models use amounts that are so small as to be unlikely to increase participation rates, going by the observations presented here. These vouchers are redeemed nevertheless (in the present case, $12.6 \%$ of vouchers with the lowest face value), i.e. redemption of all these vouchers must be termed a deadweight loss. This outcome is relevant also because the response to a high 
level of voucher redemption in a number of real-life voucher models was to decrease the face values continually in order to contain the volume of expenditure. If the results presented here are taken seriously, adjustments of this kind may stabilize the volume of expenditure of public funds but will negate any benefit of the measure in terms of added utility.

The comparisons interpreted thus far included year-earlier course attendance as a control variable. The question as to whether the voucher increased the educational participation of subjects with no history of adult education participation can be verified directly. We used multinomial logistic regression to test the impact of vouchers on adult education activity, using a reference group consisting of subjects who did not engage in adult education in either of the years studied (see Table 6). The data shows that intermediate- and high-value vouchers produced a significant increase in adult education participation in the subpopulation of subjects who took part in adult education in 2006 and not in 2005, which is a definite endorsement of the voucher system in terms of the stated aims.

\subsection{Determining the deadweight loss}

The deadweight loss of the voucher experiment can be calculated but not observed directly, i.e. we cannot distinguish between windfall gains and bona fide additional uptake of adult education in the subjects who redeemed vouchers. However, by means of comparison with the control group, we can generate expected values for adult education participation among the various subject categories and hence calculate the deadweight loss for those subsets. In relation to the total experimental population, this means that, without the experiment, we would have had to assume an adult education participation of approximately $34 \%$ in that population. With the vouchers, the level is about $6 \%$ points higher. However, it is necessary to take into account that approximately $18 \%$ of subjects in the experimental group redeemed a voucher. In other words, the conclusion is that about $60 \%$ of redeemed vouchers were used for adult education/training that the subjects would have financed themselves in any case without the vouchers, as in the control group (see Table 7). Of interest is a comparison of windfall 
gains broken down by prior educational attainment levels. It is highly evident that the deadweight loss increases significantly in association with rising prior educational attainment level. Thus it can be seen that, although subjects with an educational attainment level equal to compulsory schooling demonstrated a below-average voucher redemption rate $(9.5 \%)$, subjects in this category used the vouchers for a bona fide increase in adult education participation in almost two-thirds of cases. The voucher redemption rate was almost twice as high for university graduates (21.1\%), but voucher use in this subset can be described as a deadweight loss in $91.4 \%$ of cases. In other words, in absolute terms, this subset ultimately used fewer vouchers for a genuine rise in adult education participation than the subset of individuals with the lowest educational attainment levels.

\subsection{Multiple courses}

The voucher effect has been investigated to date only on the basis of a $0 / 1$ specification, i.e. yes or no, adult education or no adult education. The fact is that some individuals who engage in adult education attended more than one fee-based course. However, multiple participation is not as widespread as might be expected. The control group shows that, normally, approximately three-quarters $(73.6 \%)$ of individuals attend only one fee-based course within a one-year period. Of the remaining $25 \%, 73 \%$ attended two courses and only $7.1 \%$ of individuals who participated in adult education within a one-year period attended three or more courses. Comparing the control group with the experimental group, and subdividing the experimental group into the subset who redeemed the voucher and the subset who did not, shows that the number of individuals attending more than one course within a one-year period rose approximately $9 \%$ points among the voucher users (see Table 8). Multinomial regressions on the number of courses attended show (see Table 9 that only subjects with highest-value vouchers were significantly more likely to attend multiple courses. Hence, vouchers not only encourage individuals to participate in education who would not otherwise do so, but also encourage individuals with a history of adult education to increase their adult education uptake still further. 


\subsection{Employer participation in paying for adult education}

All SLFS adult education participation surveys conducted to date show that approximately half $(53.4 \%)$ of fee-based adult education is funded partly or totally by the employer. Among employed individuals - generally the sole beneficiaries of employer funding -, this was the case for $58.5 \%$ of courses in 2006. Employer funding is of twofold interest in this experiment. These items of interest are, firstly, the impact of voucher issuance on employer funding, and secondly, the extent to which employer funding explains attendance of courses for which voucher recipients did not redeem their voucher.

The first question is easily answered by applying regression to the probability of receiving employer funding for a course (see Table 10). The voucher has no significant impact on that probability. Accordingly, the employer-funded adult education rates are virtually identical in the control and experimental group. This result means that voucher issuance had no effect on employer behavior, which also means that employers had no involvement in the course attendances prompted by voucher receipt. On the other hand, this result must also be seen against the backdrop of the experimental design. A crowding out of employer funding by public funding would be likely only if vouchers were introduced on a long-term basis.

$55.5 \%$ of those who received a voucher and attended a fee-based course but did not redeem the voucher to pay for the course were recipients of employer funding, i.e. were not at all dependent on the voucher. This leaves $45.5 \%$ of individuals who engaged in adult education activity without using the voucher. These subjects had either already started a course before receiving the voucher or did not wish to redeem the voucher. This subset would be a potential source of an additional deadweight loss in the event of permanent introduction of a voucher system.

\section{Conclusions}

Irrespective of whether government intervention in the adult education market is economically justified, interventions of this kind are common practice in many countries today. The popularity of government measures to promote and 
support adult education contrasts starkly with the sparse evidential basis for the efficacy of such measures. In cases where ex post evaluations are available, these are generally based on qualitative surveys of participants and as such are of little use in evaluating impact. The randomized field experiment with adult education vouchers presented here therefore closes a major knowledge gap in terms of the impact of financial incentives on participation in adult education. Thus, before the experiment presented here, it was unclear whether financial incentives would cause increased participation in adult education, because the redemption of vouchers in real-life models could be entirely attributed to windfall gains. Moreover, it was unclear whether and to what extent money matters at all in prompting individuals with low educational attainment to participate in adult education.

Much thought was invested in producing a realistically designed study to ensure that experimental outcomes were not biased by artifactual behaviors introduced by study settings. The authors endeavored in all respects to approximate as closely as possible the launch of a real-life voucher model. In addition, the realistic setting ensured that the subjects were unaware that they were taking part in an experiment. The control group was observed in their natural environment and unaffected by the experiment.

Of the experimental outcomes, the following three are particularly striking:

Firstly, the vouchers raised adult education participation in the experimental group by approximately $20 \%$. As already mentioned, this causal effect could not be expected a priori, and therefore shows that adult education and training activities can in fact be stimulated by offering money. It is also worth noting in this connection that the very realistically designed advice option had no significant impact on voucher redemption. Hence, it was the financial support and not the advice option that increased the uptake of adult education, and the financial support produced its effect with or without the advice option. This is a surprising outcome given the importance accorded in the literature to the provision of information in connection with adult education participation. The 
result suggests that the efficacy of existing support measures might need to be investigated and evaluated more rigorously.

Secondly, voucher demand was price-sensitive, i.e., the face value of the voucher is a determining factor. It is useful to note here that, though small face values did not raise the level of participation in adult education, they were nevertheless redeemed, albeit to a small extent. Hence, low-value vouchers generated a deadweight loss only. The educational policy relevance of the realization that an effective voucher system calls for fairly high minimum voucher values should not be underestimated. At the upper end of the value scale, it was seen that, although very high values prompted individuals to take multiple courses, an intermediate voucher value is enough to generate a causal effect in terms of increased participation. These results show that excessively low voucher values are neither effective nor efficient, and excessively high values are effective but probably not efficient. Thus, it is worth investing careful planning in choosing the precise voucher value. This proposed procedure is in contrast to hitherto observed educational policy practice, which is generally based on the maximum financial framework available (i.e., financial volume, not voucher values) rather than on efficiency considerations.

Thirdly, the voucher system raised the adult education participation of individuals with low educational attainment and those with no active history of involvement in adult education. The experiment also discloses a definite positive correlation between the amount of the deadweight loss and the voucher recipient's educational attainment level. In other words, the higher the educational attainment level, the greater the redemption rate and the higher the deadweight loss. Hence, the causal effect in terms of raising participation is highest, relatively speaking, for individuals with low educational attainment. This means that formal educational attainment would be the best criterion for excluding a subset from voucher receipt and hence facilitating maximum effectiveness and efficiency of the tool.

Naturally, a number of open questions remain after this experiment. We hope 
to resolve some of them in further research. Future evaluations will look at whether the type and content of adult education funded by the vouchers differ from the type and content of education paid for without vouchers, and will seek to identify any short-term effects of adult education activity. The latter will take place in 2007 with the input of information from the latest survey of the experimental and control group in 2007.

Other questions cannot be answered by this experiment. These include longerterm dynamic effects that would come with any real-life launch of a voucher model. Whereas there is unlikely to be any major increase in the causal effect produced by vouchers in terms of increasing adult education participation, a further increase of the deadweight loss is likely. Introduction of a permanent voucher system would also be expected to impact on employer behavior. Finally a limited experiment is not sufficient to investigate the behavior of adult education providers. This would take a long-term experiment as providers would be unlikely to have the means or will to respond to a short-term change in demand.

\section{References}

[1] Angrist, J. (2004). American education research changes tack, Oxford Review of Economic Policy, 20(2), pp. 198-212.

[2] Bassanini, A. et al. (2005). Workplace Training in Europe, IZA Discussion Paper No. 1640 (also published in: Brunello, Garibaldi and Wasmer (eds.), Education and Training in Europe, Oxford University Press, 2007, Ch. 8 $13)$.

[3] Bassanini, A. and Brunello, G. (2008). Is training more frequent when wage compression is higher? Evidence from the European Community Household Panel, Labour Economics, 15, pp. 272-290.

[4] Bettiner, E. and Slonim, R. (2006). Using experimental economics to measure the effects of a natural educational experiment on altruism, Journal of Public Economics, 90(8-9). pp. 1625-48. 
[5] Bollens, J. et al. (2005). Het stelsel van de pleidingscheques gewikt en gewogen, HIVA/DTEW: Leuven.

[6] Brunello, G. (2001). On the Complementarity between Education and Training in Europe, IZA Working Paper No. 309 (also published in: D. Checchi, C. Lucifora (eds.), Education, Training and Labour Market Outcomes in Europe, MacMillan 2003).

[7] Brunello, G. and De Paola, M. (2009). Is there an underprovision of training?, Empirical Research in Vocational Education and Training, 1(1), forthcoming.

[8] Conti, G. (2005). Training, productivity and wages in Italy, Labour Economics, 12 , p. $557-576$.

[9] Cook, T.D. (2003). Why have educational evaluators chosen not to do randomized experiments?, Annals of the American Academy of Political and Social Science, 589, pp. 114-149.

[10] Cunha et al. (2005). Interpreting the evidence on life cycle skill formation, IZA Discussion Paper No. 1675.

[11] EIM (2005). Policy instruments to foster training of the employed, Final report Lifelong Learning, EIM Business \& Policy Research, Rotterdam.

[12] Falk, A. (2007). Gift exchange in the field, Econometrica, 75 (5), pp. 15011511.

[13] Fehr, E. and Goette, L. (2007). Do workers work more if wages are high? Evidence from a randomized field experiment, American Economic Review, 97(1), pp. 298-317.

[14] Gneezy, U. and List, J.A. (2006). Putting behavioural economics to work: testing for gift exchange in labor markets using field experiments, Econometrica, 74 (5), pp. 1365-1384.

[15] Heckman, J. et al. (2005). Earnings Functions, Rates of Return and Treatment Effects: The Mincer Equation and Beyond, IZA Discussion Paper No. 1700. (also published in E. Hanushek and F. Welch (eds.), Handbook of the Economics of Education, North-Holland: 2006). 
[16] Kling, J., Liebman, J.B. and Katz, L.F. (2007). Experimental analysis of neighborhood effects, Ecomometrica, 75(1), pp. 83-119.

[17] Krueger, A. and Zhu, P. (2004). Another look at the New York City school voucher experiment, American Behavioral Scientist, 47(5), pp. 658-698.

[18] Lachmayr, N. (2004). Bildungsgutschein der AK Wien, Daten und zentrale Ergebnisse der TeilnehmerInnenbefragung 2004, öibf: Wien.

[19] Ladd, H.F. (2002). School vouchers: A critical review, Journal of Economic Perspectives, 16(4), pp. 3-24.

[20] Levitt, S.D. and List, J.A. (2008). Field experiments in economics: The past, the present, and the future, NBER Discussion paper No. 14356.

[21] List, J.A. (2007). Field experiments: a bridge between lab and naturally occurring data, Advances in Economic Analysis \& Policy, 6(2) Article 8.

[22] Manski, C. F. (2005). Social Choice with Partial Knowledge of Treatment Response. Princeton University Press: Princeton.

[23] Meier, S. (2006). Does framing matter for conditional cooperation? Evidence from a natural field experiment, B.E. Journals in Economic Analysis and Policy, 5(2), pp. 1-19.

[24] Oakly, A. (2003). Using Random Allocation to Evaluate Social Interventions: Three Recent U.K. Examples, Annals of the American Academy of Political and Social Science, 589, pp. 170-189.

[25] OECD (2003). Beyond Rhetoric: Adult Learning Policies and Practices, Paris: OECD.

[26] OECD (2004a). Co-financing Lifelong Learning: Towards a Systemic Approach, OECD, Paris.

[27] OECD (2004b). Taxation and Lifelong Learning, in: Education Policy Analysis, OECD, Paris, pp. 1-28.

[28] Oosterbeek, H. (1998). Innovative ways to finance education and their relation to lifelong learning, Education Economics, 6(3), pp. 219-251. 
[29] Oosterbeek, H. and Patrinos, H.A. (2009). Financing Lifelong Learning, Empirical Research in Vocational Education and Training, 1(1), forthcoming.

[30] Pischke, J.-S. (2004). The Impact of the School Year on Student Performance and Earnings: Evidence from the German short school years, CEE Discussion Papers 0034, Centre for the Economics of Education, LSE.

[31] Rothstein, J. and Rouse, C.E. (2007). Constrained after college. Student loans and early career occupational choices. NBER Discussion Paper No. 13117.

[32] Rubin, D. (1974). Estimating causal effects of treatments in randomized and nonrandomized studies, Journal of Educational Psychology, 66(5), pp. 688-701.

[33] Silles, M.A. (2007). Adult education and earnings: evidence from Britain, Bulletin of Economic Research, 59(4), pp. 313-326.

[34] Tappeiner, G. and Trompedeller, I. (2002). Experiment "Bildungsgutschein", Erfahrungen im Südtirol, Education Permanente, 36(4), pp. 26-30.

[35] Vignoles, A., Galindo-Rueda, F. and Feinstein, L. (2004). The labour market impact of adult education and training: a cohort analysis, Scottish Journal of Political Economy, 51(2), pp. 266-280.

[36] Viitanen, T.K. (2007). Public versus private provision of daycare. An Experimental Evaluation. IZA Discussion Paper No. 3009.

[37] Webbink, D. (2005). Causal effects in education, Journal of Economic Surveys, 19(4), pp. 535-560.

[38] Winterhager, H., Heinze, A. and Spermann, A. (2006). Deregulating job placement in Europe: a microeconometric evaluation of an innovative voucher scheme in Germany; Labour Economics, 13, pp. 505-17.

[39] Wolter, S.C. et al. (2007). Nachfrageorientierte Finanzierung in der Weiterbildung, Trendbericht No. 7, SKBF: Aarau. 


\section{A Tables}

Table 2: Redemption rates

\begin{tabular}{l|c} 
Variables & Redemption rate in \% \\
\hline Voucher & 18.4 \\
Voucher 200 & 12.6 \\
Voucher 750 & 21.0 \\
Voucher 1500 & 21.7 \\
Age $>40$ & 19.45 \\
Age $<40$ & 17.62 \\
Woman & 21.43 \\
Man & 14.66 \\
No Advice & 19.78 \\
Advice & 17.06 \\
Prior educational attainment & \\
Compulsory School & 9.45 \\
Upper secondary level & 17.08 \\
Tertiary level & 26.32
\end{tabular}


Table 3: Adult education behavior broken down by experimental and control group Probit regression: Marginal effects at mean values

Dependent variable: Course participation in 2006

\begin{tabular}{lcccc}
\hline \hline & Experimental group & Control group \\
\hline Independent variables & Coeff. & $\begin{array}{c}\text { Standard } \\
\text { error }\end{array}$ & Coeff. & $\begin{array}{c}\text { Standard } \\
\text { error }\end{array}$ \\
\hline Voucher 750 & 0.042 & 0.034 & - & - \\
Voucher 1500 & 0.050 & 0.034 & - & - \\
Course participation in 2005 & $0.238^{* *}$ & 0.028 & $0.295^{* *}$ & 0.010 \\
Vocational training & $0.099^{*}$ & 0.048 & $0.072^{* *}$ & 0.016 \\
Matura & $0.234^{* *}$ & 0.064 & $0.105^{* *}$ & 0.024 \\
Non-academic tertiary degree & $0.232^{* *}$ & 0.057 & $0.181^{* *}$ & 0.022 \\
University & $0.201^{* *}$ & 0.064 & $0.206^{* *}$ & 0.023 \\
Woman & $0.077^{* *}$ & 0.029 & $0.056^{* *}$ & 0.010 \\
Swiss & $0.086^{\dagger}$ & 0.046 & $0.076^{* *}$ & 0.014 \\
Age & 0.011 & 0.011 & $0.007^{\dagger}$ & 0.004 \\
Age squared & -0.000 & 0.000 & $-0.000^{*}$ & 0.000 \\
City of Basel & 0.030 & 0.062 & 0.021 & 0.021 \\
City of Bern & 0.038 & 0.059 & $0.047^{*}$ & 0.021 \\
Cities of Geneva and Lausanne & 0.007 & 0.057 & -0.009 & 0.016 \\
Urban Ticino & 0.064 & 0.081 & $-0.065^{* *}$ & 0.016 \\
City of Zurich & $0.078^{*}$ & 0.038 & 0.014 & 0.014 \\
Other cities & 0.053 & 0.040 & 0.017 & 0.015 \\
Non-employed & $-0.111^{* *}$ & 0.037 & $-0.115^{* *}$ & 0.013 \\
\hline
\end{tabular}

\begin{tabular}{lcc}
\hline Number of observations & $1^{\prime} 888$ & $14^{\prime} 403$ \\
Log-likelihood & $-1^{\prime} 155.91$ & -8020.29 \\
$\chi_{(22)}^{2} / \chi_{(20)}^{2}$ & 165.72 & $1^{\prime} 529.39$ \\
Observed probability & 0.403 & 0.338 \\
Estimated probability & 0.392 & 0.314 \\
Pseudo $R^{2}$ & 0.092 & 0.130 \\
\hline
\end{tabular}

Levels of significance : $\quad \dagger: 10 \% \quad *: 5 \% \quad * *: 1 \%$

Dummies for marital status and for children under age 5 . 
Table 4: Causal effect of adult education vouchers in increasing participation Probit regression: Marginal effects at mean values Dependent variable: Course participation in 2006

\begin{tabular}{|c|c|c|c|c|}
\hline Independent variables & Coeff. & $\begin{array}{c}\text { Standard } \\
\text { error }\end{array}$ & Coeff. & $\begin{array}{c}\text { Standard } \\
\text { error }\end{array}$ \\
\hline Voucher & $0.055^{* *}$ & 0.015 & - & - \\
\hline Voucher 200 & - & - & 0.027 & 0.024 \\
\hline Voucher 750 & - & - & $0.064^{* *}$ & 0.025 \\
\hline Voucher 1500 & - & - & $0.075^{* *}$ & 0.025 \\
\hline Course participation in 2005 & $0.288^{* *}$ & 0.009 & $0.288^{* *}$ & 0.009 \\
\hline Vocational training & $0.076^{* *}$ & 0.016 & $0.076^{* *}$ & 0.016 \\
\hline Matura & $0.123^{* *}$ & 0.023 & $0.124^{* *}$ & 0.023 \\
\hline Non-academic tertiary degree & $0.188^{* *}$ & 0.020 & $0.188^{* *}$ & 0.020 \\
\hline University & $0.207^{* *}$ & 0.022 & $0.207^{* *}$ & 0.022 \\
\hline Woman & $0.058^{* *}$ & 0.010 & $0.058^{* *}$ & 0.010 \\
\hline Swiss & $0.079^{* *}$ & 0.014 & $0.079^{* *}$ & 0.014 \\
\hline Age & $0.007^{*}$ & 0.004 & $0.007^{*}$ & 0.004 \\
\hline Age squared & $-0.000^{* *}$ & 0.000 & $-0.000^{* *}$ & 0.000 \\
\hline City of Basel & 0.022 & 0.020 & 0.022 & 0.020 \\
\hline City of Bern & $0.046^{*}$ & 0.020 & $0.046^{*}$ & 0.020 \\
\hline Cities of Geneva and Lausanne & -0.006 & 0.016 & -0.006 & 0.016 \\
\hline Urban Ticino & $-0.057^{* *}$ & 0.016 & $-0.056^{* *}$ & 0.016 \\
\hline City of Zurich & 0.022 & 0.013 & 0.022 & 0.013 \\
\hline Other cities & 0.020 & 0.014 & 0.021 & 0.014 \\
\hline Non-employed & $-0.114^{* *}$ & 0.013 & $-0.114^{* *}$ & 0.013 \\
\hline Number of observations & \multicolumn{2}{|c|}{$16 ' 291$} & \multicolumn{2}{|c|}{$16^{\prime} 291$} \\
\hline Log-likelihood & \multicolumn{2}{|c|}{$-9 ' 197.05$} & \multicolumn{2}{|c|}{$-9^{\prime} 195.43$} \\
\hline$\chi_{(21)}^{2} / \chi_{(23)}^{2}$ & \multicolumn{2}{|c|}{ 1'679.65 } & \multicolumn{2}{|c|}{$1^{\prime} 680.48$} \\
\hline Observed probability & \multicolumn{2}{|c|}{0.346} & \multicolumn{2}{|c|}{0.346} \\
\hline Estimated probability & \multicolumn{2}{|c|}{0.324} & \multicolumn{2}{|c|}{0.324} \\
\hline Pseudo $R^{2}$ & \multicolumn{2}{|c|}{0.125} & \multicolumn{2}{|c|}{0.125} \\
\hline Levels of significance : $\quad \dagger: 10 \%$ & $*: 5 \%$ & k* : $1 \%$ & & \\
\hline
\end{tabular}


Table 5: Causal effect of adult education vouchers in increasing participation in the employed population only

Probit regression: Marginal effects at mean values

Dependent variable: Course participation in 2006

\begin{tabular}{|c|c|c|c|c|}
\hline Independent variables & Coeff. & $\begin{array}{c}\text { Standard } \\
\text { error }\end{array}$ & Coeff. & $\begin{array}{l}\text { Standard } \\
\text { error }\end{array}$ \\
\hline Voucher & $0.053^{* *}$ & 0.017 & - & - \\
\hline Voucher 200 & - & - & 0.016 & 0.027 \\
\hline Voucher 750 & - & - & $0.048^{\dagger}$ & 0.028 \\
\hline Voucher 1500 & - & - & $0.093^{* *}$ & 0.029 \\
\hline Course participation in 2005 & $0.273^{* *}$ & 0.011 & $0.274^{* *}$ & 0.011 \\
\hline Vocational training & $0.068^{* *}$ & 0.019 & $0.068^{* *}$ & 0.019 \\
\hline Matura & $0.079^{* *}$ & 0.029 & $0.080^{* *}$ & 0.029 \\
\hline Non-academic tertiary degree & $0.145^{* *}$ & 0.024 & $0.145^{* *}$ & 0.024 \\
\hline University & $0.132^{* *}$ & 0.027 & $0.133^{* *}$ & 0.027 \\
\hline Woman & $0.035^{*}$ & 0.014 & $0.035^{*}$ & 0.014 \\
\hline Swiss & $0.072^{* *}$ & 0.017 & $0.072^{* *}$ & 0.017 \\
\hline Age & $-0.003^{* *}$ & 0.001 & $-0.003^{* *}$ & 0.001 \\
\hline City of Basel & 0.030 & 0.023 & 0.029 & 0.023 \\
\hline City of Bern & $0.037^{\dagger}$ & 0.022 & $0.038^{\dagger}$ & 0.022 \\
\hline Cities of Geneva and Lausanne & $-0.033^{\dagger}$ & 0.018 & $-0.032^{\dagger}$ & 0.018 \\
\hline Urban Ticino & $-0.074^{* *}$ & 0.020 & $-0.074^{* *}$ & 0.020 \\
\hline City of Zurich & 0.011 & 0.015 & 0.011 & 0.015 \\
\hline Other cities & 0.023 & 0.016 & 0.023 & 0.016 \\
\hline Part-time & 0.010 & 0.014 & 0.010 & 0.014 \\
\hline Hourly wage (logarithmized) & $0.070^{* *}$ & 0.016 & $0.069^{* *}$ & 0.016 \\
\hline Self-employed & 0.028 & 0.019 & 0.028 & 0.019 \\
\hline Employee & & & & \\
\hline in managerial position & 0.011 & 0.016 & 0.011 & 0.016 \\
\hline with supervisory function & 0.015 & 0.015 & 0.015 & 0.015 \\
\hline Tenure & -0.000 & 0.001 & -0.000 & 0.001 \\
\hline Size of firm $10-49$ & $0.034^{*}$ & 0.016 & $0.034^{*}$ & 0.016 \\
\hline Size of firm 50-99 & 0.006 & 0.020 & 0.006 & 0.020 \\
\hline Size of firm over 100 & $0.047^{* *}$ & 0.017 & $0.048^{* *}$ & 0.017 \\
\hline Sideline job & 0.031 & 0.021 & 0.031 & 0.021 \\
\hline Number of observations & \multicolumn{2}{|c|}{$12^{\prime} 996$} & \multicolumn{2}{|c|}{$12^{\prime} 996$} \\
\hline Log-likelihood & \multicolumn{2}{|c|}{$-7^{\prime} 555.89$} & \multicolumn{2}{|c|}{-7552.91} \\
\hline$\chi_{(40)}^{2} / \chi_{(42)}^{2}$ & \multicolumn{2}{|c|}{ 1'499.45 } & \multicolumn{2}{|c|}{1508.25} \\
\hline Observed probability & \multicolumn{2}{|c|}{0.383} & \multicolumn{2}{|c|}{0.383} \\
\hline Estimated probability & \multicolumn{2}{|c|}{0.365} & \multicolumn{2}{|c|}{0.365} \\
\hline Pseudo $R^{2}$ & \multicolumn{2}{|c|}{0.127} & \multicolumn{2}{|c|}{0.127} \\
\hline
\end{tabular}

Dummies for sectors, marital status and for children under age 5 . 
Table 6: Adult education participation in 2006 as a function of adult education activity in 2005; Multinomial logistic regression: Marginal effects at mean values Reference category: No course participation in 2005 and 2006

\begin{tabular}{|c|c|c|}
\hline Independent variables & Coefficient & Standard error \\
\hline \multicolumn{3}{|c|}{ Course participation in 2006 only } \\
\hline Voucher 200 & 0.019 & 0.018 \\
\hline Voucher 750 & $0.044^{*}$ & 0.018 \\
\hline Voucher 1500 & $0.061^{* *}$ & 0.019 \\
\hline \multicolumn{3}{|c|}{ Course participation in 2005 and 2006} \\
\hline Voucher 200 & 0.016 & 0.019 \\
\hline Voucher 750 & 0.027 & 0.020 \\
\hline Voucher 1500 & 0.006 & 0.019 \\
\hline \multicolumn{3}{|c|}{ Course participation in 2005 only } \\
\hline Voucher 200 & 0.011 & 0.020 \\
\hline Voucher 750 & 0.011 & 0.021 \\
\hline Voucher 1500 & -0.020 & 0.019 \\
\hline Number of observations & \multicolumn{2}{|c|}{$16^{\prime} 291$} \\
\hline Log-likelihood & \multicolumn{2}{|c|}{$-19^{\prime} 453.21$} \\
\hline$\chi_{(69)}^{2}$ & \multicolumn{2}{|c|}{1313.78} \\
\hline Pseudo $R^{2}$ & \multicolumn{2}{|c|}{0.057} \\
\hline 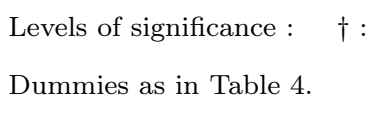 & * : $5 \%$ & $* *: 1 \%$ \\
\hline
\end{tabular}


Table 7: Estimated deadweight loss by prior educational attainment level

Distribution of redeemed vouchers as a percentage of all vouchers per group

\begin{tabular}{l|cc|c}
$\begin{array}{l}\text { Prior educational } \\
\text { attainment }\end{array}$ & $\begin{array}{c}\text { Deadweight } \\
\text { loss in \% }\end{array}$ & $\begin{array}{c}\text { Causal } \\
\text { effect } \\
\text { in \% }\end{array}$ & $\begin{array}{c}\text { Deadweight loss } \\
\text { as a \% of re- } \\
\text { deemed vouchers }\end{array}$ \\
\hline Compulsory School & 3.7 & 6.1 & 37.7 \\
Upper secondary level & 8.7 & 6.6 & 56.8 \\
Vocational training & 9.4 & 5.0 & 65.1 \\
Matura & 5.5 & 13.7 & 28.7 \\
Tertiary level & 17.7 & 5.5 & 76.3 \\
Non-academic tertiary degree & 16.6 & 7.7 & 68.3 \\
University & 19.6 & 1.8 & 91.4 \\
\hline Total & 10.0 & 6.5 & 60.5
\end{tabular}

Table 8: Number of courses attended within the past year (in \%)

\begin{tabular}{c|c|c|c}
$\begin{array}{c}\text { Number of } \\
\text { courses }\end{array}$ & $\begin{array}{c}\text { Control } \\
\text { group }\end{array}$ & $\begin{array}{c}\text { Experimental } \\
\text { group }\end{array}$ & $\begin{array}{c}\text { Voucher } \\
\text { redeemed }\end{array}$ \\
\hline 1 & 73.6 & 73.1 & 64.7 \\
2 & 19.3 & 20.9 & 23.6 \\
$\geq 3$ & 7.1 & 6.0 & 11.7 \\
\hline & 100 & 100 & 100
\end{tabular}


Table 9: Number of courses attended

Multinomial logistic regression: Marginal effects at mean values

Reference category attended no courses

\begin{tabular}{|c|c|c|}
\hline Independent variables & Coefficient & Standard error \\
\hline \multicolumn{3}{|l|}{1 course attended } \\
\hline Voucher 200 & $0.047^{\dagger}$ & 0.025 \\
\hline Voucher 750 & $0.054^{*}$ & 0.025 \\
\hline Voucher 1500 & $0.044^{\dagger}$ & 0.026 \\
\hline Vocational training & $0.063^{* *}$ & 0.015 \\
\hline Matura & $0.065^{* *}$ & 0.022 \\
\hline Non-academic tertiary degree & $0.126^{* *}$ & 0.021 \\
\hline University & $0.138^{* *}$ & 0.022 \\
\hline \multicolumn{3}{|l|}{2 courses attended } \\
\hline Voucher 200 & -0.000 & 0.010 \\
\hline Voucher 750 & 0.015 & 0.011 \\
\hline Voucher 1500 & $0.032^{*}$ & 0.013 \\
\hline Vocational training & 0.013 & 0.008 \\
\hline Matura & $0.038^{* *}$ & 0.014 \\
\hline Non-academic tertiary degree & $0.036^{* *}$ & 0.013 \\
\hline University & $0.040^{* *}$ & 0.014 \\
\hline \multicolumn{3}{|l|}{3 or more courses attended } \\
\hline Voucher 200 & -0.004 & 0.004 \\
\hline Voucher 750 & 0.000 & 0.004 \\
\hline Voucher 1500 & 0.009 & 0.006 \\
\hline Vocational training & $0.007^{\dagger}$ & 0.004 \\
\hline Matura & $0.030^{* *}$ & 0.010 \\
\hline Non-academic tertiary degree & $0.015^{*}$ & 0.007 \\
\hline University & $0.024^{*}$ & 0.010 \\
\hline Number of observations & \multicolumn{2}{|c|}{$16^{\prime} 097$} \\
\hline Log-likelihood & \multicolumn{2}{|c|}{$-12^{\prime} 571.46$} \\
\hline$\chi_{(72)}^{2}$ & \multicolumn{2}{|c|}{$1^{\prime} 686.96$} \\
\hline Pseudo $R^{2}$ & \multicolumn{2}{|c|}{0.098} \\
\hline $\begin{array}{l}\text { Levels of significance : } \dagger: 10 \% \\
\text { Dummies as in Table } 4\end{array}$ & \multicolumn{2}{|c|}{$* *: 1 \%$} \\
\hline
\end{tabular}


Table 10: Employer funding of adult education Probit regression: Marginal effects at mean values Dependent variable: Employer funding of course

\begin{tabular}{|c|c|c|}
\hline Independent variables & Coefficient & Standard error \\
\hline Voucher 200 & -0.018 & 0.020 \\
\hline Voucher 750 & -0.022 & 0.019 \\
\hline Voucher 1500 & -0.010 & 0.020 \\
\hline Course participation in 2005 & $0.169^{* *}$ & 0.009 \\
\hline Vocational training & $0.053^{* *}$ & 0.016 \\
\hline Matura & $0.050^{*}$ & 0.024 \\
\hline Non-academic tertiary degree & $0.083^{* *}$ & 0.021 \\
\hline University & $0.075^{* *}$ & 0.023 \\
\hline Woman & $-0.018^{\dagger}$ & 0.011 \\
\hline Swiss & $0.051^{* *}$ & 0.012 \\
\hline Age & $-0.002^{* *}$ & 0.001 \\
\hline City of Basel & 0.001 & 0.018 \\
\hline City of Bern & 0.014 & 0.017 \\
\hline Cities of Geneva and Lausanne & $-0.030^{*}$ & 0.013 \\
\hline Urban Ticino & $-0.071^{* *}$ & 0.013 \\
\hline City of Zurich & -0.013 & 0.012 \\
\hline Other cities & -0.008 & 0.012 \\
\hline Part-time & $-0.032^{* *}$ & 0.011 \\
\hline Hourly wage (logarithmized) & $0.071^{* *}$ & 0.012 \\
\hline Self-employed & $-0.079^{* *}$ & 0.014 \\
\hline \multicolumn{3}{|l|}{ Employee } \\
\hline in managerial position & 0.011 & 0.012 \\
\hline with supervisory function & 0.015 & 0.011 \\
\hline Tenure & $0.004^{* *}$ & 0.001 \\
\hline Tenure squared & $-0.000^{*}$ & 0.000 \\
\hline Size of firm $10-49$ & $0.053^{* *}$ & 0.014 \\
\hline Size of firm 50-99 & $0.059^{* *}$ & 0.018 \\
\hline Size of firm over 100 & $0.090^{* *}$ & 0.015 \\
\hline Sideline job & -0.004 & 0.017 \\
\hline
\end{tabular}

\begin{tabular}{lc}
\hline Number of observations & $12^{\prime} 568$ \\
Log-likelihood & $-5 ' 668.86$ \\
$\chi_{(43)}^{2}$ & $1^{\prime} 191.09$ \\
Observed probability & 0.215 \\
Estimated probability & 0.178 \\
Pseudo $R^{2}$ & 0.133 \\
\hline Levels of significance : $\quad \dagger: 10 \% \quad *: 5 \% \quad * *: 1 \%$ \\
Dummies for sectors, marital status and for children under age 5.
\end{tabular}

